\title{
Disconnecting reticulocortical pathways: Amnestic effects on visual habits in the rat*
}

\section{ROBERT THOMPSON and JOHN H. PUCHEU \\ Louisiana State University, Baton Rouge, La. 70803}

Discrete bilateral electrolytic lesions destroying the subthalamic area in the rat produced profound losses in retention of a brightness and a pattern discrimination habit. Lesions damaging the anterolateral portions of the thalamus had significantly smaller effects on retention. These results were interpreted as pointing to the priority of a subthalamic route over a thalamic route in the functional activation of the neocortex by the brainstem reticular formation.

It is becoming increasingly clear that the integrity of certain portions of the brainstem reticular formation (BSRF) is necessary for the expression of a wide variety of learned responses in the white rat (Thompson \& Henderson, 1971; Thompson \& Thorne, 1973). In fact, the distribution of the critical regions mapped by the lesion method (see Thompson \& Thorne, 1973) roughly parallels the trajectory of the ascending reticular activating system (Moruzzi \& Magoun, 1949) and conspicuously overlaps the course of the ascending cholinergic reticular system (Shute \& Lewis, 1967).

The participation of the BSRF in supporting learned responses raises the question concerning the identity of the specific conduction pathway connecting this complex neural system with the neocortex. Neurophysiological (Starzl, Taylor, \& Magoun, 1951), neuroanatomical (Scheibel \& Scheibel, 1958), and neurochemical (Shute \& Lewis, 1967) studies suggest that the influence of the BSRF upon the neocortex may be exerted either through a thalamic route or through an extrathalamic (subthalamic) route. The purpose of the current study was to examine the relative contributions of each to the expression of previously learned visual discrimination habits in the rat.

\section{METHOD}

Adult male albino rats of the Wistar strain were initially trained to approach a white stimulus card and avoid an adjacent black stimulus card (Problem WB) in a Thompson-Bryant (1955) discrimination apparatus. Under the motive of escape from a footshock, a response to the unlocked white card admitted $S$ to the goalbox, whereas a response to the locked black card was automatically punished by mild footshock. Eight trials were given daily with an intertrial interval of $60 \mathrm{sec}$. The criterion of learning consisted of no more than one error in 2 consecutive days. Upon reaching the criterion of learning, the Ss were then required to approach a horizontal black and white striped card and avoid an adjacent vertical black and white striped card (Problem HV), the training procedure being the same as that used for Problem WB. Following learning, one group (Group ST) sustained bilateral electrolytic lesions of the subthalamus at the level of the subthalamic nucleus, a second group (Group T) received bilateral lesions to the anterolateral portions of the thalamus, and the third group (Group NC) served as normal

*This research was supported in part by a grant from the Graduate Council of Research, Louisiana State University. controls. After a 2-week recovery (or rest) period, the Ss were given a retention test which consisted of relearning the two discrimination problems in the order in which they were originally mastered. Retention was measured in percentage error savings scores, using the conventional formula. Following the retention test, histological verification of the locus and extent of the lesions was made. Details of the surgical and histological procedures have been reported elsewhere (Thompson, 1971).

\section{RESULTS}

Two Ss were discarded from Group ST beacuse their lesions damaged only the dorsal sector of the subthalamus (Forel's Field $\mathrm{H}_{1}$ ), including the ventral portion of the nucleus ventralis and the underlying medial lemniscus. The remaining six Ss suffered lesions of the subthalamic area (Forel's Fields $\mathrm{H}_{1}$ and $\mathrm{H}_{2}$ ) in addition to the subthalamic nucleus (see Fig. 1A). In two cases, the lesions damaged the underlying cerebral peduncle, but in no case did the lesions extend caudally

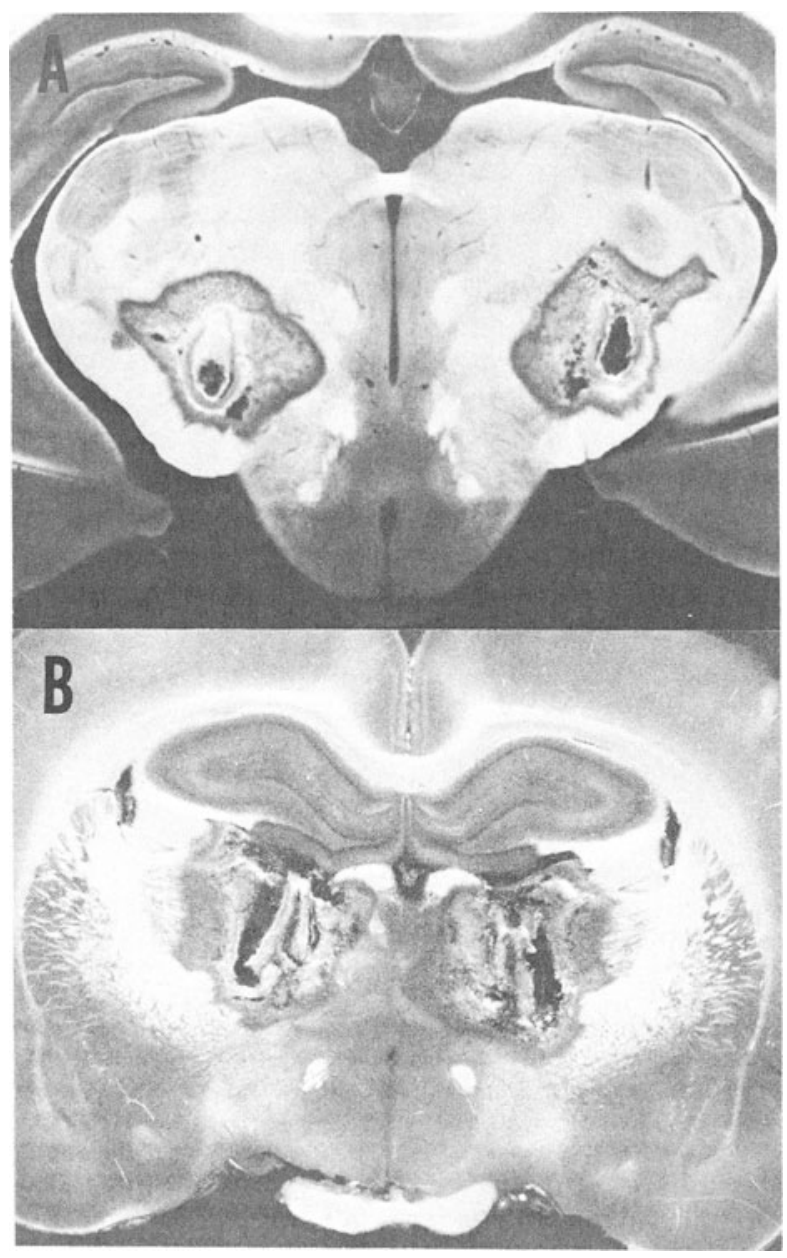

Fig. 1. Photographs of unstained sections showing lesions of the subthalamic area (A) in one rat (Problem WB $=-20 \%$, Problem HV $=-200 \%$ ) and the anterior thalamus (B) in one rat (Problem WB $=88 \%$, Problem HV $=67 \%$ ). 
into the substantia nigra. laterally into the lateral geniculate bodies, or medially into the lateral hypothalamic area. The three Ss of Group $\mathrm{T}$ suffered large lesions to the anterior half of the thalamus, which damaged portions of the nucleus anterior ventralis, anterior medialis, anterior dorsalis, and reticularis (see Fig. 1B). In all three cases, the lesions extended caudally into the medial dorsal thalamic nucleus.

No obvious disturbances in wakefulness were observed in any of our brain-damaged Ss. In fact, all appeared alert and responsive to tactile and auditory stimuli $24 \mathrm{~h}$ after surgery. Temporary increases in emotionality, as gauged by heightened startle reflexes and excessive struggling in response to handling. were observed in three Ss of Group ST and one S of Group T. Transient aphagic and adipsic disorders were seen in two $S$ s of Group ST and one S of Group T. No motor deficits were observed. However, while all subthalamic Ss actively explored the surface of the observation table, the thalamic Ss showed virtually no exploratory activity: this difference persisted throughout the observation nerind of 2 weeks.

Seven of the eight Ss of Group NC earned error savings scores on both habits in excess of $90 \%$. In contrast. five of the six Ss in Group ST earned savings scores below 26\% of Problem WB and four of the six earned negative savings scores on Problem HV. The three Ss of Group T earned savings scores between $57 \%$ and $88 \%$ on both habits. The Mann-Whitney test disclosed that Group ST was significantly inferior to Group T as well as Group NC in retention of both visual habits (ps <.05). The differences between Group $T$ and Group NC were also significant (ps $<.05$ ).

During the retention test, all brain-damaged Ss showed good orientation to the discriminanda prior to a choice, and all made adaptive correction responses following an error. However, they did require more than the usual number of footshocks to initiate forward progression culminating in approach to one of the stimulus cards. The thalamic Ss required footshocks because they tended to "freeze" within the startbox and/or choice chamber. The subthalamic Ss, in contrast, required footshocks because they tended to "explore" the various parts of the startbox and/or choice chamber.

\section{DISCUSSION}

The principal finding of this study was that lesions of the subthalamus (including Forel's Fields $\mathrm{H}_{1}$ and $\mathrm{H}_{2}$ and the subthalamic nucleus) markedly disrupt retention of brightness as well as pattern discrimination habits in the albino rat. The fact that a previous study (Thompson, 1969) failed to obtain serious amnestic effects on visual habits following lesions of the dorsomedial (Forel's Field $\mathrm{H}_{1}$ ) or lateral (zona incerta) portions of the subthalamus suggests the possibility that Forel's Field $\mathrm{H}_{2}$ and the underlying subthalamic nucleus constitute a critical subthalamic focus for visual discrimination deficits. Further support for this possibility comes from the observation that the two Ss of the current study sustaining lesions of the dorsal aspect of the subthalamus exhibited excellent retention (savings scores in excess of 90 ) of Problems WB and HV.

It is important to note that subthalamic lesions in the rat also impair retention of nonvisual tasks. including latch box problems
(Spiliotis \& Thompson. 1973) and a simple make habit (Thompson. 1973). ${ }^{1}$ (ats with subthalamic lesions have likewise been reported to show disturbances in the performance of various laboratory tasks (Adey. Walter, \& Lindsley. 1962).

Since lesions of the BSRF (Thompson \& Thorne. 1973) also impair retention of a wide variety of learned tasks, and since ascending reticular fibers have been shown to pass through the subthalamus (Scheibel \& Scheibel, 1958; Shute \& Lewis. 1967). disconnection of reticulocortical influences could conceivably provide the basis for the observed amnestic effects of subthalamic lesions. Furthermore, our finding that large anterior thalamic lesions produced considerably smaller effects on retention than subthalamic lesions would suggest the priority of a subthalamic route over a thalamic route with respect to the functional activation of cortical areas by the BSRF.

It must be emphasized. however, that alternative explanations are available. Lindsley and his associates (Lindsley. Barton. \& Atkins. 1970; Lindsley, Zaroodny, \& Morton, 1967), for example. have amassed compelling evidence suggesting that impairments in learning and other attentive behaviors following subthalamic lesions are due to disjoining descending fiber systems en route to the BSRF, particularly those originating within the neocortex. limbic forebrain areas, and the corpus striatum. While this possibility cannot be entirely ruled out. it is significant to note that damage to the anterior half of the neocortex, cingulate cortex. hippocampo-septal sy'stem. amygdala, or caudate nucleus does not seriously disrupt performance of visual discrimination habits in the rat (see Thompson. 1969).

\section{REFERENCES}

Adey, W. R., Walter, D. O., \& Lindsley, D. F. Subthalamic lesions. Effects on learned behavior and correlated hippocampal and subcortical slow-wave activity. Archives of Neurology, 1962, 6, 194-207.

Lindsley, D. F., Barton, R. J., \& Atkins, R. J. Effects of subthalamic lesions on peripheral and central arousal thresholds in cats. Experimental Neurology, 1970, 26, 109-119.

Lindsley, D. F., Zaroodny, T., \& Morton, T. H. Effects of subthalamic lesions on sensory-evoked potentials in the reticular formation and sensorimotor cortex. Experimental Neurology, 1967, 17, 210-220.

Moruzzi, G., \& Magoun, H. W. Brain stem reticular formation and activation of the EEG. Electroencephalography \& Clinical Neurophysiology, 1949, 1, 455-473.

Scheibel, M. E., \& Scheibel, A. B. Structural substrates for integrative patterns in the brain stem reticular core. In $\mathrm{H}$. $\mathrm{H}$. Jasper (Ed.), Reticular formation of the brain. Boston: Little. Brown, 1958.

Shute, C. C. D., \& Lewis, P. R. The ascending cholinergic reticular system: Neocortical, olfactory and subcortical projections. Brain, 1967, 90, 497-520.

Spiliotis, P. H., \& Thompson, R. The "manipulative response memory system" in the white rat. Physiological Psycholog! $1973,1,101-114$.

Starzl, T. E., Taylor, C. W., \& Magoun, H. W. Ascending conduction in reticular activating system, with special reference to the diencephalon. Journal of Neurophysiology. $1951,14,461-477$.

Thompson, R. Localization of the "visual memory system" in the white rat. Journal of Comparative \& Physiological Psychology Monograph, 1969, 69, 1-29.

Thompson, $R$. Introducing subcortical lesions by electrolytic methods. In R. D. Myers (Ed.), Methods in psychobiology. New York: Academic Press, 1971.

Thompson, R., \& Bryant, J. H. Memory as affected by activity of the relevant receptor. Psychological Reports, 1955, 1 . 393-400.

Thompson, R.. \& Henderson, T. C. Pontine reticular formation lesions: Amnestic effects on learned habits in the rat. Psychonomic Science, 1971, 25, 169-170.

Thompson, R., \& Thorne, B. M. Brainstem reticular formation lesions: Amnestic effects on learning habits in the rat. Physiological Psychology, 1973, 1, 61-70.

\section{NOTE}

1. Thompson, R. Unpublished manuscript, 1973.

(Received for publication June 7. 1973.) 